\title{
Dental Technologists Association (DTA)
}

Supplied by the Dental Techologists Association, Cheltenham, UK

\section{W} ho founded the society and why? In 1984 the General Dental Council (GDC) took the bold step to establish the Dental Technicians Education \& Training Advisory (DTETAB) with a remit to review and make recommendations about the education and training of dental technicians, the suitability of that training and how it fitted with the demands of providing dental services at that time. A major part of the role of DTETAB was maintaining the Voluntary Register of Dental Technicians, the forerunner of the statutory register.

The inaugural meeting of the Board took place in January 1986 and was chaired by Margaret Seward (later Dame Margaret Seward). The GDC was clear that its active involvement would be for three years only. In 1989 DTETAB became an independent body, with responsibility for running and financing the organisation.

DTETAB was renamed as the Dental Technicians Association in 2002, in readiness for a slightly different role post statutory registration. Since 2012 the organisation has been known as the Dental Technologists Association (DTA) run by voluntary dental technicians for dental technicians and we are committed to keeping members in touch with what is going on in dental technology and the wider dental arena as well as facilitating our members with the tools they need to stay educated and compliant.

\footnotetext{
How many members are there and how do you become one?

The DTA represent approximately $25 \%$ of GDC registered dental technologists throughout the UK. The best way for an individual dental technician to get their voice heard with profession regulators and government bodies is to join the DTA. It's really easy to join via the DTA website; we have membership packages to suit everyone that works within the dental laboratory
}

- from students, apprentices, laboratory assistants through to fully qualified dental technicians and clinical dental technicians registered in the UK.

\section{What are the aims of the society?}

Our vision is to advance standards within dental technology for the benefit of the oral healthcare of the nation by:

- Providing advice guidance and support to members

- Raising awareness and promoting an exchange of views on key issues affecting the dental profession.

\section{Key objectives}

1. Develop and support members, and the dental technology profession

2. Encourage and promote education, including CPD

3. Forge links with other organisations

4. Promote views to relevant external organisations

5. Adopt and share best practice

6. Provide benefits and employment opportunities. Develop and maintain roles and responsibilities.

What services do you provide your members? The DTA represent the best interests of all UK dental technologists with one voice, whether qualified or in training and providing lifelong learning opportunities, advice, guidance and support to our members.

Dental technology is in exciting times with the emergence of digital dental technology and clinical dental technology, but there is also an ever-increasing number of challenges - not least the changes to ECPD and MHRA regulations from MDD to MDR. We keep members up to date on all the important information. Our voluntary management team regularly meet and continually influence and raise the profile of dental technology with decision makers including regulators,

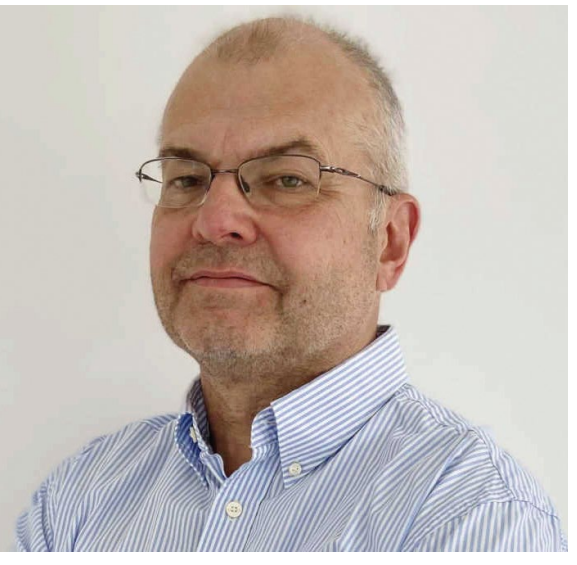

Barry Tivey, DTA President 2020-2022

educational providers and various groups and we continue to be actively involved in various national initiatives, consultations, campaigns and activities.

Open to dental technicians and clinical dental technicians living in the United Kingdom, we provide members with a one stop shop including a plethora of benefits (access to over 20 hours of verifiable CPD per year, PDP, Log Book, DTA journals The Technologist and Articulate, exclusive professional indemnity insurance offers, 24-hour helpline, support, guidance documents and more...) and packages to suit and support students throughout their education; newly qualified individuals taking the next step in starting their career; and experienced professionals, making it easy for them to stay compliant no matter where they are on their journey.

\section{What are the society's greatest achievements?}

The DTA has been an established representative organisation for over 30 years, representing and educating registered dental technologists and students of the craft; guiding the membership through profession and regulatory changes and the continuous advancement of digital dental technology.

From 31 July 2006 the GDC opened the register for dental technicians and clinical dental technicians and the DTA played a vital role in overseeing the statutory registration. After the two-year transitional period, the titles 'dental technician' and 'clinical dental technician' became protected and can only be used by those who are trained with a recognised qualification for GDC registration. Dental technicians and clinical dental 
1 technicians became recognised as highly skilled professionals by the GDC and as crucial members of the oral healthcare team.

What does the society hope to achieve in the next few years?

1. Continue to support dental technologists through the COVID-19 pandemic, an extremely difficult situation that UK dental technicians and clinical dental technicians have found themselves in. Whilst it appears that dentists are being supported via the NHS to maintain their income, the country is likely to lose many of its professional dental technologists due to the lack of government support for these essential members of the dental team and we have voiced this concern continually. The fear is there will be insufficient skilled and knowledgeable dental technologists left within the UK's oral healthcare team to provide the custom-made dental appliances that UK patients need and therefore the health of the population will likely suffer greatly for some time to come.

2. The DTA continues to raise awareness of the dental technology profession and the vital work that dental technicians do as an integral part of the oral healthcare team in the UK. Dental technologists are unsung heroes; they continually develop their skills and knowledge as required to create precise, custom-made dental appliances and are often the promoters of innovation and support to the clinicians. Their work requires a high level of manual dexterity and attention to detail and an application of applied aesthetic values and many dentists encourage a close working relationship with their dental technician to maintain that excellence of supply and support. Each patient is unique, and no two appliances are the same, each being an individually designed and created restoration magically created by the dental technician away from the clinic. Therefore, the work is carefully crafted by skilled hands, fine-tuning each piece to the exact specification to make sure the device is comfortable, aesthetic and mechanically sound, then rigorously quality assured prior to placing on the market (as required by MHRA - MDR) ready for fitting by the clinician. Dental technologists work with specialised equipment in the dental laboratory from simple hand tools, mechanical devices though to CAD/CAM technology, using a range of dedicated and approved dental materials. They use their knowledge of the properties and application of each of these materials in order to design and construct custom made dental devices to the prescription and with absolute precision and traceability of materials and assessment in the production process (as required by MHRA - MDR for dental appliances). Many patients are unaware that it is the dental technologist that creates their one off new custom-made dental device (be that a denture, crown, bridge or orthodontic appliance) and provides the confidence to the clinical team that comes with that perfect effective custom-made dental device solution for each individual patient who often just see the final item presented at the fit stage by the dentist.

3. To allow for a broadened dental technologist scope of practice to enhance patients' oral healthcare as the profession and integrated technology continues to evolve. Although the current GDC Scope of Practice describes what all registrants including dental technologists are trained and competent to do, it at times currently constrains patient care. It describes the areas in which dental technologists have the knowledge, skills and experience to practise safely and effectively in the best interests of patients as well as describing additional skills dental technicians could develop. Dental technologists are often asked to work outside their role for the sole benefit of patients in providing their new custom-made dental devices but are restricted by the existing Scope of Practice, whilst dentists often encourage dental technologists to just solve the problem in the laboratory. They find that they have overstepped their scope, so some amendments are required to legally allow enhanced patient care.

4. The Dental Technologist Association (DTA) continues to provide qualityassured lifelong learning to its membership by a variety of media and to the requirements set out by the GDC for this as Enhanced Continuing Professional Development (ECPD). The DTA's planned programme of ECPD covers the required field of activity and also we maintain the quality assurance demanded of dental CPD providers.

To learn more visit www.dta-uk.org, email info@dta-uk.org or call 01242461931.
GDC publishes online resource for managers and employers

The General Dental Council (GDC) has published Supporting the dental team, ${ }^{1}$ an online resource for employers, managers, and contractors of dental services.

Employers and managers of dental professionals, who may not be GDC registrants, play a significant role in ensuring patients receive high standards of service and care. While the regulator recognises there is much good work already taking place to this end in all kinds of dental settings, it says its new guide is designed to complement and support, pulling together useful information from a range of places.

GDC Head of Public Policy, Osama Ammar, said: 'While the GDC does not regulate dental businesses, working alongside our stakeholders we saw a gap in the information and support that was available to dental team managers and employers. By providing this additional information in one place, we felt we could assist them in their understanding of the professional responsibilities of the dental team and encourage activities that will enhance patient care.

'I'd like to thank the many stakeholders who worked with us on this project, and we look forward to further developing the resource in the coming years.'

In addition to information to support dental professionals in understanding and meeting their regulatory responsibilities, the resource also covers wellbeing of the dental team and handling feedback and concerns.

\section{Reference}

1. General Dental Council. Supporting the dental team - a guide for managers and employers. 2021. Available at: https://www.gdc-uk.org/ information-standards-guidance/supportingthe-dental-team (accessed 11 April 2021) 